\section{José Félix Merizalde}

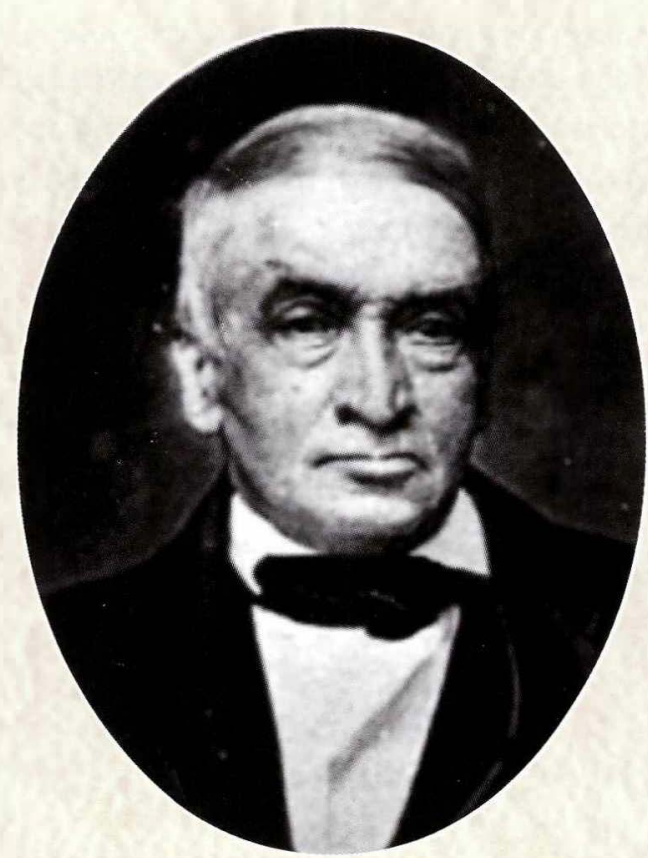

Por el Doctor Luis María Rivas Merizalde

Nieto del Prócer y Profesor de Anatomía de la Facultad de Medicina

D. Miguel Ignacio de Merizalde y Santiesteban fue enviado por el Comercio español á estudiar la manera más fácil y barata de recoger y transportar la corteza de quina. Encontró en los montes de Tena, Pasto y otros lugares árboles semejantes á los de Loja, lo comunicó á D. José Celestino Mutis, y éste solicitó y obtuvo del Gobierno español el título de Descubridor de las quinas, en competencia con D. Sebastián López Ruiz, quien habiéndose hecho acompañar por el sirviente del Doctor Merizalde recogió cortezas que presentó al Virrey Flórez con la misma solicitud. De este ilustre profesor de medicina fue hijo el Doctor José Félix Merizalde.

Nació en Santafe el 19 de Marzo de 1787; de su instrucción primaria fue encargado el padre candelario Fray Nicolás Sierra, pues no cuidándose el Gobierno ni los padres de familia de educar la juventud, se carecía de escuelas donde pudiéranse aprender las primeras letras.

Cursó literatura en el Colegio Seminario de San Bartolomé, donde se distinguió, á la par que estudiante modelo, por su genio alegre y chispeante; la crónica amena de los claustros está llena de esos episodios que pasarán á la posteridad, y nuestros padres relataron con verdadera fruición.

Terminados sus estudios de literatura pasó al Colegio Mayor de Nuestra Señora del Rosario; allí asistió á las lecciones de medicina que dictaba el Doctor Vicente Gil y Tejada, dignísimo sucesor del padre Isla, verdadero fundador de los estudios de medicina, y se distinguió tánto que mereció el premio de \$100 dado por el Doctor Eloy Valenzuela al alumno más distinguido de la Facultad de Medicina.

Poco antes de Julio de 1810, ya terminados sus estudios de acuerdo con los reglamentos, se recibió de Doctor en Medicina y Cirugía y el 7 de Julio de 1811 contrajo matrimonio con la señorita Regina Vásquez, miembro de una respetable familia de Santafé; de tan feliz matrimonio tuvo dieziocho hijos, de los cuales hoy sóloexistendos: la señora Adelaida Merizalde de Rivas y la señora Matilde Merizalde de Gaitán.

Desde el principio abrazó con entusiasmo la santa causa de nuestra Independencia nacional. El 24 de Noviembre de 1812 entró al ejército patriota como Alférez y como médico por lo cual hubo de abandonar la cátedra de medicina fundada por él á sus expensas y que desempeñaba gratuitamente en el Colegio de San Bartolomé. En el combate que tuvo lugar el 9 de Enero de 1813 fue ascendido á Teniente, y habiendo caído prisionero de las fuerzas realistas el 6 de Mayo de 1816, fue sentenciado á servir gratuitamente en los hospitales de virolentos y más tarde en los militares de San Fernando y Las Aguas, bajo la despótica inspección del Cirujano Mayor del Ejército, Fernández de la Reguera, teniendo ocasión de servir con especial cuidado á los patriotas que también habían caído prisioneros. El 10 de Agosto de 1819, de nuevo en el Ejército, desempeñó gratuitamente el cargo de Director Inspector general de hospitales, y desde el 15 de Octubre del año siguiente, ascendido á Capitán, prestó sus servicios como médico, asimilado á Sargento Mayor hasta 1831. "En este último empleo, dice el General Rafael Mendoza, Secretario de Guerra y Marina de la Unión, así como en los que había desempeñado con anterioridad, se distinguió siempre, como que los ejercía empleando su talen- 
to y conocimientos en la ciencia médica. El 5 de Septiembre, y como homenaje á sus servicios, se le confirió el despacho de Teniente Coronel, y dejó de estar en servicio el 16 de Enero de 1833."

En 1817 Sámano, que gobernaba en Santafé, dispuso que los médicos residentes en esta ciudad se reuniesen cada mes en casa del Intendente para perfeccionar, por medio de la discusión, las ciencias médicas y naturales, fundando así la primera Academia; á ella perteneció el Doctor Merizalde.

En 1833, siendo Médico Mayor del Ejércitó, se le siguió una causa, de la cual fue absuelto por la Suprema Corte Marcial, por mal trato á los enfermos; esto y el no estar de acuerdo con el Comandante General, hizo que renunciase el puesto, dedicándose al ejercicio de la profesión y á la enseñanza, dictando lecciones de Anatomía, Cirugía, Patología Interna y Fisiología, en la misma cátedra que él había fundado en 1812 en San Bartolomé. Entonces creó una clase pública y gratuita de Medicina Legal, correspondiéndole el honor de ser el fundador de conferencias públicas en Bogotá. El mismo año fue nombrado visitador de boticas y reglamentó el servicio de las farmacias.

El Doctor Pablo Broc, francés, abrió en 1823 un curso de Anatomía práctica y vendió al Gobierno unas cuantas figuras anatómicas por la suma de $\$ 2,112$. Esta compra fue censurada por la prensa por el Doctor Merizalde, quien sostenía con razón que siendo las lecciones prácticas sobre el cadáver, esas figuras estaban de más, y en el año siguiente publicó El desengaño anatómico, destinado á probar que el Doctor Broc no había enseñado Anatomía.

Varias fueron las cátedras regentadas por él en los Colegios del Rosario y de San Bartolomé. Fue miembro fundador del profesorado universitario en 1827 . Siendo miembro de la Junta de Inspección y Gobierno de la Universidad Central, compuesta de los más ilustres Profesores, espontáneamente fue recomendado por ciudadanos notables para ser nombrado Rector.

En 1830 hizo parte de la comisión de la Facultad que redactó Observaciones sobre la fiebre epidémica que se presentó en el cuatrimestre último de 1830 y preseptos de Higiene, folleto destinado á propalar los medios de evitar y curar la enfermedad.

En 1840, nombrado Jefe de la Oficina de vacunación publicó el Tratamiento de las viruelas y se hizo acreedor á la consideración del Gobierno y á la gratitud pública, por los servicios que prestó durante la epidemia y por la organización del servicio de vacunación.

En 1874 hizo parte de la "Sociedad de propagación de la vacuna," y desde 1859, siendo Director de la Sección hospitalaria de la Sociedad de San Vicente de Paúl, propagó gratuitamente el pus vacuno y prestó sus servicios profesionales á los enfermos que había en el hospital.

En varias ocasiones fue miembro de la Municipalidad y de la Cámara de la Provincia de Bogotá, de la Cámara de Representantes y del Senado, del cual fue Presidente en 1844. En Reemplazo del señor Gómez fue miembro de la famosa Convención de Ocaña.

Celoso de las libertades públicas, decidido defensor de las Leyes y amigo personal del General Santander, se le atribuyó participación en la política que dio origen á la conspiración de Septiembre, por lo cual fue confinado á Tunja, conspiración que condenó, como se ve en la página 509 de sus Elementos de Higiene: "Nunca recordará nuestra posteridad el 25 de Septiembre de 1828 sin horrorizarse y sin condolerse de una loca y presuntuosa juventud que pudo morir en los campos del honor."

En 1846 hizo parte del Colegio de Medicina, sostenido con las rentas de la escuela universitaria, y en el 49 escribió Método curativo del cólera asiático ó celeste.

La ley de 1850, Marzo 15, estableció que no era preciso tener título para ejercer profesiones, exceptuando la de farmaceuta.

El Doctor Merizalde, en asocio de los Doctores Andrés M. Pardo y Antonio Vargas Reyes, venciendo las dificultades que la ley presentaba, estableció una Escuela de Medicina, dictando sus lecciones en el Rosario y en San Bartolomé. En 1850, siendo grande el número de jóvenes que ejercían la medicina sin tener conocimiento de ella, con grave perjuicio para el público, se unió á los Doctores Pardo, Librado Rivas y Francisco Bayón para dictar lecciones de medicina en los Colegios oficiales. 
El Doctor Merizalde era un hombre alegre y jovial; se le atribuyen Los Emigrados, coplas que con él cantaba el General Santander en 1821, y no obstante su constante consagración al estudio, el incansable celo por el noble ejercicio de su profesión y los múltiples cargos públicos que siempre desempeñó con acierto, las anécdotas chistosas que se cuentan de él y su trato siempre afable y cortés, demuestran que la fatuidad y petulancia nunca son inherentes á la ciencia ni prueba irrefutable de vasta ilustración.

Muchas fueron las publicaciones del Doctor Merizalde; fuera de las ya mencionadas, escribió: En 1822, Origen de los papeles contra la secta masónica; 1823 Receta para la epidemia presente de tos y sarampión.

El Empírico de Bogotá, defendiendo el cuerpo médico ultrajado por el Doctor López Ruiz, que no perdonó al señor Mutis el haberle usurpado, como él decía, el título de Descubridor de las quinas, que sólo pertenecía al padre del Doctor Merizalde.

En 1825 escribió El Noticiosote, y en 1827 un periódico El Chasqui.

En 1828 el Epítome de los elementos de Higiene y en 1831, Elementos de Patología general, libros ambos llenos de curiosas observaciones personales que merecieron ser escogidos para textos de enseñanza en la Universidad Central.

En 1832 Disertaciones sobre la Elefancia, en 1834 los Cuadros Nosológicos, y en 1835 Historia fúnebre de la enfermedad y muerte del Doctor Castillo Rada.

En 1836 La tirocelia y la sirocelia vindicada, polémica con el Doctor Miguel Ibáñez, en la cual éste obtuvo el triunfo.

En 1837 Receta para curar el Sarampión, y muchas otras publicaciones.

La caridad y el desinterés del Doctor Merizalde han sido proverbiales. En los Anales de la Sociedad de San Vicente de Paúl de la cual fue varias veces Presidente, se encuentra su nombre á cada paso. El señor Doctor Juan Buenaventura Ortiz, en su exposición histórica, refiriéndose especialmente al año de 1861, dice (1) “De tiempo atrás había el Doctor Merizalde puesto su persona, su bolsillo, su despensa y su botica á disposición de los pobres; ahora ya no le parecía bastante hacerlo privadamente; y publicó un aviso en que ofrecía á todos los necesitados sus servicios médicos, los de dos profesores más de su familia (2) y de otro discípulo suyo, advirtiendo que las recetas que ellos dieran se despacharían en la botica de su pertenencia y que las utilidades de ésta serían en parte, á lo menos para el Hospital; y para dar más fuerza á su promesa bautizó su establecimiento con el expresivo nombre de Botica de San Vicente de Paúl.

Para terminar copiaré textualmente lo que dice el Doctor Ibáñez en las Memorias para la Historia de la Medicina en Santafe de Bogotá.

"El Doctor Merizalde se distinguió por su caridad, su generosidad y su desinterés. No obstante el haber ejercido su profesión por espacio de cincuenta y ocho años, llegó el invierno de su vida, sin poseer bienes de fortuna y agobiado por el trabajo y por los años, pasó sus últimos días casi en la indigencia. Después de la guerra de 1860 quedó sin recursos el Hospital de San Vicente de Paúl, y sólo pudo sostenerse, merced á las limosnas que recibió y al Doctor Merizalde que, amuinado ya y casi indigente, dividía con los pobres el escaso pan de sus hijos (actas de la Sociedad de San Vicente de Paúl.)

"El nombre del Doctor Merizalde es popular y querido entre nosotros; y sus discípulos y amigos lo recuerdan con gratitud y cariño.

"Los servicios que prestó á la causa de la Independencia; los que prestó á la enseñanza médica; el largo tiempo que sirvió las enfermerías de los hospitales y casas de beneficencia; sus numerosas publicaciones científicas y políticas, en lo que brilla más que la forma literaria ó lo elevado del estilo, su amor al progreso y su patriotismo; su probidadpersonal y su honradezpolítica, sus elevadas dotes morales; su ilustración; su carácter filantrópico; su amor al trabajo y su bien decir y sal ática en la conversa-

(1) Memoria histórica por el Doctor Antonio José Uribe, pág. 80.

(2) El Doctor José Pablo Merizalde, su hijo: el Doctor Librado Rivas, su hijo político, y el Señor jorge Gaitán, que también fue después su hijo político. 
ción familiar, fueron cualidades que le grangearon el aprecio de la sociedad, que han hecho su memoria digna de perpetuarse en la posteridad, y que han impedido que el polvo del olvido cubra la losa de su tumba.

"El 19 de Marzo de 1868, el día mismo que cumplía 81 años de peregrinación en la tierra dedicados al trabajo, al estudio y á hacer el bien, falleció en Bogotá, en la Quinta de Bolívar, dejando el noble ejemplo de haber cumplido con las obligaciones que le impidieron su profesión, los elevados cargos públicos que desempeñó y el ser jefe de una numerosa y distinguida familia."

Julio de 1910.

\section{ELIXIR de VIRGIMIL IYRDaHL}

A base de Hammamelis Dirginica y de capsicum brasiliense

Enfermedades de la edad crítica

Del sistema renoso

Várices y úlceras varicosas

Almorranas

Edemas crónicas

Congestiones

Hemorragias

\section{Algarine Nyrdah1

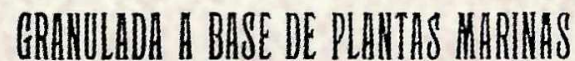

REEMPLAZANDO

EL ACEITE de HIGADO de BACALAO

TOLerancla Perfect

Sabor agradable

\section{Grageas de Ibogaina Hyndahl \\ TRATAMIENTO DE LAS}

Atonías musculares y nerviosas

Neurastenia

Dilatación y Astenia cardíaca

Para evitar falsificaoiones exijase la firma de garnntía, Nyrdahl

Reproducción del aviso publicado en Repertorio de Medicina y Cirugía volumen I Número 9 de junio 15 de 1910. 